\title{
Study on Notch Sensitivity of Fracture Properties of Concrete Containing Nano-SiO 2 Particles and Fly Ash
}

\author{
Peng Zhang, ${ }^{1}$ Qiao-Yan Guan, ${ }^{2}$ Chen-Hui Liu, ${ }^{1}$ and Qing-Fu Li ${ }^{1}$ \\ ${ }^{1}$ School of Water Conservancy and Environment Engineering, Zhengzhou University, Zhengzhou 450001, China \\ ${ }^{2}$ Department of Civil Engineering, Zhengzhou Institute of Aeronautical Industry Management, Zhengzhou 450015, China \\ Correspondence should be addressed to Peng Zhang; zhangpeng8008@gmail.com
}

Received 23 October 2013; Accepted 13 November 2013

Academic Editor: Hui Xia

Copyright @ 2013 Peng Zhang et al. This is an open access article distributed under the Creative Commons Attribution License, which permits unrestricted use, distribution, and reproduction in any medium, provided the original work is properly cited.

\begin{abstract}
The fracture parameters and fracture relational curves of the concrete containing nano- $\mathrm{SiO}_{2}$ and fly ash with different relative notch depth of the notched beam specimens were measured by means of three-point bending method. The results indicate that the relative notch depth of the notched specimens has great effect on $a_{c}, K_{\mathrm{IC}}^{\mathrm{ini}}, K_{\mathrm{IC}}^{\mathrm{un}}, G_{F}, \mathrm{CMOD}_{c}$, and the fracture relational curves of the concrete containing nano- $\mathrm{SiO}_{2}$ and fly ash. There is a tendency of increase in $a_{c}$ and $\mathrm{CMOD}_{c}$ with the increase of relative notch depth, while $K_{\mathrm{IC}}^{\mathrm{ini}}, K_{\mathrm{IC}}^{\mathrm{un}}$, and $G_{F}$ are decreasing gradually with the increase of relative notch depth of the notched beam specimens. Besides, when the relative notch depth increases from 0.2 to 0.5 , the nonlinear stage of the curve becomes shorter and shorter, and the descent stage of the curve becomes sharper and sharper. The fracture parameters of $a_{c}, K_{\mathrm{IC}}^{\mathrm{ini}}, K_{\mathrm{IC}}^{\mathrm{un}}, G_{F}$, and $\mathrm{CMOD}_{c}$ and the fracture curves are sensitive to the relative notch depth, while $\mathrm{CTOD}_{c}$ may be not sensitive to the relative notch depth of the specimens of the concrete containing nano- $\mathrm{SiO}_{2}$ and fly ash.
\end{abstract}

\section{Introduction}

Fly ash is known as a by-product of coal-burning thermal power stations, and the disposal of fly ash has become a considerable environmental problem $[1,2]$. In order to solve the environmental problem of disposing fly ash, large quantities of fly ash are proposed to be incorporated in concrete mixes. Numerous studies have been focused on the development of concrete composites containing large amounts of fly ash [3-8]. In recent years, much attention has been paid to the applications of nano-materials in civil engineering, because nanoparticles possess many special properties such as huge specific surface area and high activity due to their small size [9]. The pozzolanic activity of nano- $\mathrm{SiO}_{2}$ is more obvious than that of silica fume, and nano- $\mathrm{SiO}_{2}$ can react with calcium hydroxide $\left(\mathrm{Ca}(\mathrm{OH})_{2}\right)$ crystals, which are arrayed in the interfacial transition zone between hardened cement paste and aggregates, and produce C-S-H gel [10]. Previously, the effects of nano- $\mathrm{SiO}_{2}$ particles on different mechanical properties of concrete composites have been studied. Li et al. investigated the improvement in compressive and flexural strengths, abrasion resistance, chloride permeability, and flexural fatigue performance of concrete containing nanoparticles [11-14]. Bahadori and Hosseini studied the effects of replacing cement with colloidal amorphous silica nanoparticles on the physical and mechanical properties, durability and microstructure of concrete [15]. Givi et al. investigated the effects of $\mathrm{SiO}_{2}$ nanoparticles on both mechanical properties and physical properties of concrete and the size effects of $\mathrm{SiO}_{2}$ nanoparticles on compressive, flexural, and tensile strength of binary blended concrete [16, 17]. Heidari and Tavakoli investigated the compressive strength, and water absorption of the concrete composite using nano- $\mathrm{SiO}_{2}$ and waste ground ceramic simultaneously [18]. Their results indicate that the addition of nano- $\mathrm{SiO}_{2}$ particles greatly improves the compressive, flexural, tensile strength and toughness of concrete composites. Nanoparticles can act as heterogeneous nuclei for cement pastes, further accelerating cement hydration because of their high reactivity, as nanoreinforcement, and as nanofiller, densifying the microstructure, thereby, leading to a reduced porosity [19].

Fracture properties are extremely important for the safety and durability of concrete structures. To study crack expansion of the beam specimen of concrete, a notch should be 
TABLE 1: Properties of cement and fly ash.

\begin{tabular}{lcc}
\hline Composition (\%) & Cement & Fly ash \\
\hline Chemical compositions & & \\
$\mathrm{SiO}_{2}$ & 20.85 & 51.50 \\
$\mathrm{Al}_{2} \mathrm{O}_{3}$ & 5.32 & 18.46 \\
$\mathrm{Fe}_{2} \mathrm{O}_{3}$ & 2.69 & 6.71 \\
$\mathrm{CaO}$ & 62.97 & 8.58 \\
$\mathrm{MgO}$ & 3.66 & 3.93 \\
$\mathrm{Na}_{2} \mathrm{O}$ & 0.15 & 2.52 \\
$\mathrm{~K}_{2} \mathrm{O}$ & 0.62 & 1.85 \\
$\mathrm{SO}_{3}$ & 2.48 & 0.21 \\
$\mathrm{Physical}$ properties & & \\
Specific gravity & 3.11 & 2.16 \\
Specific surface $\left(\mathrm{cm}^{2} / \mathrm{g}\right)$ & 3287 & 2470 \\
\hline
\end{tabular}

cut in the specimen. The relative notch depth can be defined as the ratio of the notch depth to the height of the beam specimen. The conventional concrete has notch sensitivity on its fracture properties. Despite the recent efforts, few studies are available, concerning the fracture behavior of the concrete containing nano- $\mathrm{SiO}_{2}$ and fly ash; specially no significant experimental data exist on the effect of relative notch depth on fracture properties of the concrete containing $\mathrm{SiO}_{2}$ nanoparticles and fly ash. Therefore, we conducted this experimental study and measured the fracture toughness, fracture energy, crack mouth opening displacement, and crack tip opening displacement of the notched beam specimens to study the notch sensitivity of the beam specimens of the concrete containing nano- $\mathrm{SiO}_{2}$ particles and fly ash.

\section{Experimental Program}

2.1. Raw Materials. A Chinese standard (GB175-2007) [20] Portland cement Class 42.5R (which has standard compressive strength of $42.5 \mathrm{MPa}$ at the age of 28 days) was used. A Chinese standard (GB/T 1596-2005) [21] Grade I fly ash was used to make the concrete. The chemical and physical properties of the cement and fly ash are presented in Table 1. In this experimental study, amorphous nano- $\mathrm{SiO}_{2}$ with a solid content of more than $99 \%$ was used. Physical properties of the nanoparticles are presented in Table 2. Coarse aggregate with a maximum size of $20 \mathrm{~mm}$ and fine aggregate with a 2.76 fineness modulus were used. The specific gravity and silt content of the coarse and fine aggregates were 2.74 and $0.6 \%$, and 2.63 and $0.8 \%$, respectively. A high range water reducing agent was used to adjust the workability of the concrete mixture. The performance indices of the high range water reducing agent are presented in Table 3. Fly ash content and nano- $\mathrm{SiO}_{2}$ content (by mass) are $15 \%$ and $5 \%$, respectively. The mix proportion used in this study is given in Table 4.

2.2. Experimental Method. A series of notched beam specimens with the size of $100 \times 100 \times 515 \mathrm{~mm}$ were prepared to determine the fracture parameters and curves. The beam specimen was sawed from the span centre of the lower surface to produce a precutting crack, the relative notch depth of which is $0.2,0.3,0.4$, and 0.5 , respectively. All the specimens were cured for 28 days before testing. Three-point bending beam method was employed to measure the fracture parameters in this study, which is an appropriate fracture testing method [22].

2.3. Determination of Fracture Parameters. In this study, the fracture properties of concrete were evaluated by the double$K$ fracture parameters (initial fracture toughness $K_{\mathrm{IC}}^{\text {ini }}$ and unstable fracture toughness $K_{\mathrm{IC}}^{\mathrm{un}}$ ) [23] and fracture energy $G_{F}$. The effective crack length of the three-point bending beam specimen is generally used to calculate $K_{\mathrm{IC}}^{\mathrm{ini}}$ and $K_{\mathrm{IC}}^{\mathrm{un}}$, and the effective crack length can be calculated as follows [24]:

$$
a_{c}=\frac{2}{\pi} H \times \operatorname{arctg} \sqrt{\frac{E B}{32.6 P_{V \max }} \mathrm{CMOD}_{c}-0.1135},
$$

where $a_{c}$ is effective crack length of the three-point bending beam specimen, $\mathrm{m} ; P_{V \text { max }}$ is peak vertical load, $\mathrm{kN}$; $\mathrm{CMOD}_{c}$ is critical crack mouth opening displacement, $\mathrm{m} ; E$ is elastic modulus of the concrete composite, $\mathrm{MPa} ; H$ is height of the beam specimen, $\mathrm{m} ; B$ is width of the beam specimen, $\mathrm{m}$.

With the measured initial cracking load and the depth of the precutting crack of the three-point bending beam specimen, the initial fracture toughness of the concrete containing nano- $\mathrm{SiO}_{2}$ and fly ash can be calculated as follows [25]:

$$
K_{\mathrm{IC}}^{\mathrm{ini}}=\frac{3 P_{\mathrm{ini}} S \sqrt{a_{0}}}{2 B H^{2}} f\left(\frac{a_{0}}{H}\right),
$$

where $K_{\mathrm{IC}}^{\mathrm{ini}}$ is initial fracture toughness, $\mathrm{kN} / \mathrm{m}^{3 / 2} ; P_{\text {ini }}$ is initial cracking load, $\mathrm{kN} ; S$ is span length of the beam specimen, $\mathrm{m}$; $H$ is height of the beam specimen, $\mathrm{m} ; B$ is width of the beam specimen, $\mathrm{m} ; a_{0}$ is depth of the precutting crack of the threepoint bending beam specimen, $\mathrm{m} ; f\left(a_{0} / H\right)$ is a function relevant to $a_{0} / H$, the expression of which is as follows:

$$
\begin{aligned}
f\left(\frac{a_{0}}{H}\right)= & \left(1.99-\frac{a_{0}}{H}\left(1-\frac{a_{0}}{H}\right)\right. \\
& \left.\times\left[2.15-3.93 \frac{a_{0}}{H}+2.7\left(\frac{a_{0}}{H}\right)^{2}\right]\right) \\
& \times\left(\left(1+2 \frac{a_{0}}{H}\right)\left(1-\frac{a_{0}}{H}\right)^{1.5}\right)^{-1} .
\end{aligned}
$$

With the measured peak vertical load and the effective crack length of the three-point bending beam specimen, the unstable fracture toughness of the concrete containing nano$\mathrm{SiO}_{2}$ and fly ash can be calculated as follows [25]:

$$
K_{\mathrm{IC}}^{\mathrm{un}}=\frac{3 P_{V \max } S \sqrt{a_{c}}}{2 B H^{2}} f\left(\frac{a_{c}}{H}\right) \text {, }
$$

where $K_{\mathrm{IC}}^{\mathrm{un}}$ is unstable fracture toughness, $\mathrm{kN} / \mathrm{m}^{3 / 2} ; P_{V \max }$ is peak vertical load, $\mathrm{kN}$; $S$ is span length of the beam specimen, $\mathrm{m}$; $H$ is height of the beam specimen, $\mathrm{m} ; B$ is width of 
TABle 2: Physical properties of nano- $\mathrm{SiO}_{2}$.

\begin{tabular}{|c|c|c|c|c|}
\hline Average particle size (nm) & $\mathrm{SiO}_{2}$ content $(\%)$ & Specific surface area $\left(\mathrm{m}^{2} / \mathrm{g}\right)$ & Apparent density $\left(\mathrm{g} / \mathrm{cm}^{3}\right)$ & $\mathrm{PH}$ value \\
\hline 30 & 99.5 & $200 \pm 10$ & 0.055 & $5-7$ \\
\hline
\end{tabular}

TABle 3: Properties of high range water reducing agent.

\begin{tabular}{lccccc}
\hline Solid content (\%) & Total alkali content $(\%)$ & Fluidity of cement paste $(\mathrm{mm})$ & Density $\left(\mathrm{g} / \mathrm{cm}^{3}\right)$ & $\mathrm{Content}$ of $\mathrm{Cl}^{-}(\%)$ & $\mathrm{PH}$ value \\
\hline 30 & 1.2 & 260 & 1.052 & 0.078 & 4.32 \\
\hline
\end{tabular}

TABLE 4: Mix proportions of the concrete composites.

\begin{tabular}{lcccccc}
\hline $\begin{array}{l}\text { Cement } \\
\left(\mathrm{kg} / \mathrm{m}^{3}\right)\end{array}$ & $\begin{array}{c}\text { Fly ash } \\
\left(\mathrm{kg} / \mathrm{m}^{3}\right)\end{array}$ & $\begin{array}{c}\text { Nano-SiO } \\
\left(\mathrm{kg} / \mathrm{m}^{3}\right)\end{array}$ & $\begin{array}{c}\text { Fine aggregate } \\
\left(\mathrm{kg} / \mathrm{m}^{3}\right)\end{array}$ & $\begin{array}{c}\text { Coarse aggregate } \\
\left(\mathrm{kg} / \mathrm{m}^{3}\right)\end{array}$ & $\begin{array}{c}\text { Water } \\
\left(\mathrm{kg} / \mathrm{m}^{3}\right)\end{array}$ & $\begin{array}{c}\text { Water reducing } \\
\text { agent }\left(\mathrm{kg} / \mathrm{m}^{3}\right)\end{array}$ \\
\hline 395.2 & 74.1 & 24.7 & 647 & 1151 & 158 & 4.94 \\
\hline
\end{tabular}

the beam specimen, $\mathrm{m} ; a_{c}$ is effective crack length of the threepoint bending beam specimen, $\mathrm{m} ; f\left(a_{c} / H\right)$ is a function relevant to $a_{c} / H$, the expression of which is as follows:

$$
\begin{aligned}
f\left(\frac{a_{c}}{H}\right)= & \left(1.99-\frac{a_{c}}{H}\left(1-\frac{a_{c}}{H}\right)\right. \\
& \left.\times\left[2.15-3.93 \frac{a_{c}}{H}+2.7\left(\frac{a_{c}}{H}\right)^{2}\right]\right) \\
& \times\left(\left(1+2 \frac{a_{c}}{H}\right)\left(1-\frac{a_{c}}{H}\right)^{1.5}\right)^{-1} .
\end{aligned}
$$

The fracture energy is resulting from integration of the load-displacement curve per unit of the fractured surface of the specimen [26]. With the measured ultimate mid-span deflection and the relational curve of $P_{V}-\delta$ of the three-point bending beam specimen, the fracture energy of the concrete containing nano- $\mathrm{SiO}_{2}$ and fly ash can be calculated as follows [27]:

$$
\begin{gathered}
G_{F}=\frac{1}{A_{\text {lig }}}\left[W_{0}+\left(m_{1}+2 m_{2}\right) g \delta_{\max }\right], \\
A_{\text {lig }}=B\left(H-a_{0}\right),
\end{gathered}
$$

where $G_{F}$ is fracture energy, N/m; $A_{\text {lig }}$ is area of the fracture ligament of the specimen, $\mathrm{m}^{2} ; H$ is height of the beam specimen, $\mathrm{m} ; B$ is width of the beam specimen, $\mathrm{m} ; a_{0}$ is depth of the notched crack, $\mathrm{m} ; \mathrm{g}$ is gravitational acceleration $\left(g=9.8 \mathrm{~m} / \mathrm{s}^{2}\right) ; m_{1}$ is weight of the specimen between the two supports, $\mathrm{kg} ; m_{2}$ is additive weight of the loading facilities; $\delta_{\max }$ is the maximum mid-span deflection of the beam specimen, $\mathrm{m} ; W_{0}$ is area above the axis of $\delta$ and under the relational curve of $P_{V}-\delta, \mathrm{N} \cdot \mathrm{m}$. There are 6 specimens for each relative notch depth, and the average value of the 6 values of calculation is adopted as the final result.

\section{Results and Discussion}

3.1. Effect of Relative Notch Depth on Fracture Toughness. The results of the effective crack length $\left(a_{c}\right)$ of the three-point

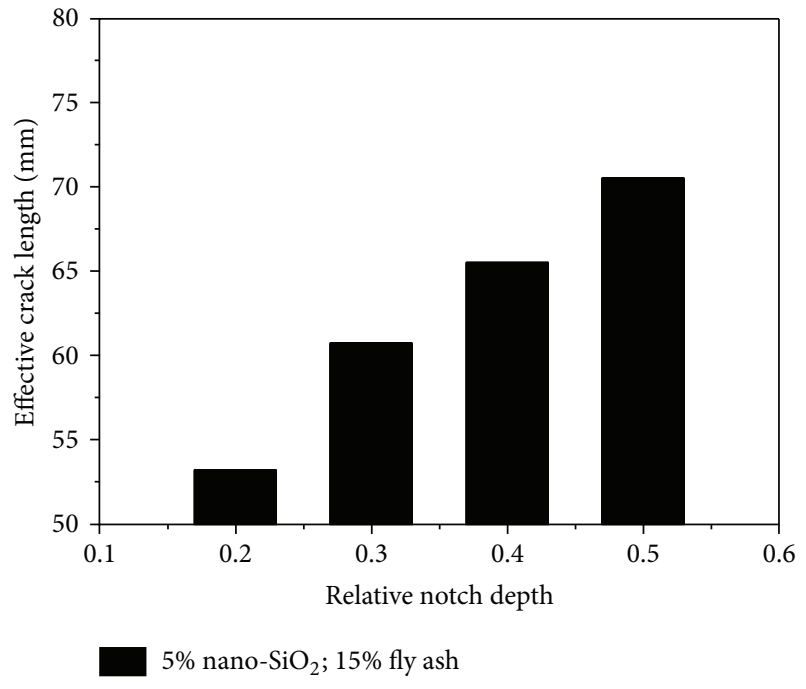

FIGURE 1: Effect of relative notch depth on effective crack length.

bending beam specimens of the concrete containing nano$\mathrm{SiO}_{2}$ and fly ash, with the curing period of $28 \mathrm{~d}$, are shown in Figure 1. The results show that the fracture parameter of $a_{c}$ is greatly sensitive to the relative notch depth of notched threepoint bending beam specimens, and the effective crack length of the specimen with smaller relative notch depth is more sensitive to the relative notch depth. However, in general, there is a tendency of increase in $a_{c}$ with the increase of relative notch depth of the specimens. Compared with the three-point bending beam specimen with 0.2 relative notch depth, the increase of $a_{c}$ is determined as $32.5 \%$ for the threepoint bending beam specimen with 0.5 relative notch depth.

To some extent, the effective crack length represents the actual length of the crack in the calculating of the fracture parameters. The actual length of the crack is longer than the depth of the precutting crack of the specimen because there is a stage of steady expanding before unstable fracture occurs, and the propagation length of the crack is the difference of the actual length of the crack and the depth of the precutting crack of the specimen. The larger the depth of the precutting 


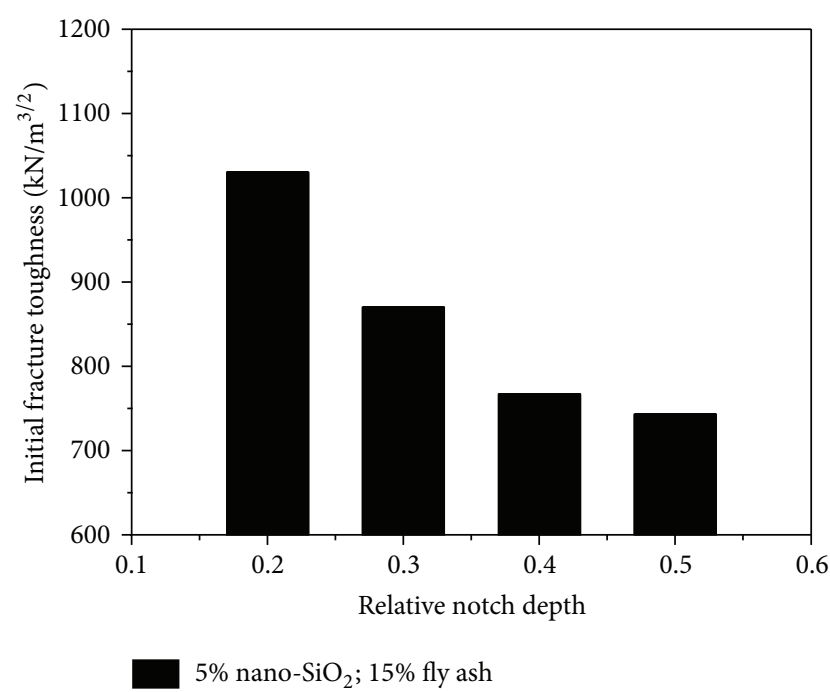

FIGURE 2: Effect of relative notch depth on initial fracture toughness.

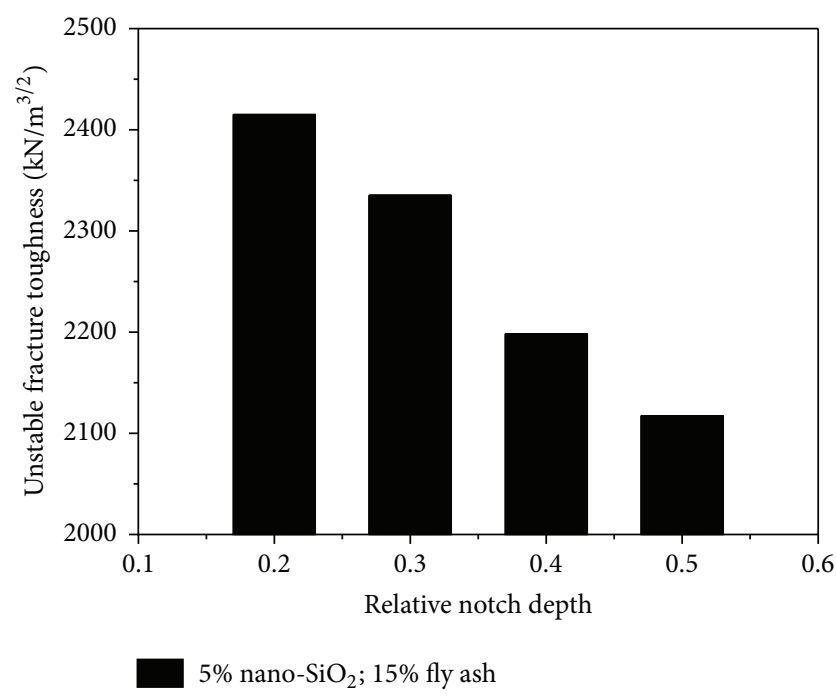

FIGURE 3: Effect of relative notch depth on unstable fracture toughness.

crack, the larger the effective crack length. Therefore, the relative notch depth of the beam specimen increases with relative notch depth.

Figures 2 and 3 illustrate the variations of initial fracture toughness $\left(K_{\mathrm{IC}}^{\mathrm{ini}}\right)$ and unstable fracture toughness $\left(K_{\mathrm{IC}}^{\mathrm{un}}\right)$ of the concrete containing nano- $\mathrm{SiO}_{2}$ and fly ash at 28 days curing period with the increase of the relative notch depth of notched three-point bending beam specimen, respectively. As can be seen from the figures, the three-point bending specimens with larger relative notch depth have lower $K_{\mathrm{IC}}^{\mathrm{ini}}$ and $K_{\mathrm{IC}}^{\mathrm{un}}$ compared with those specimens with higher relative notch depth. Both of $K_{\mathrm{IC}}^{\mathrm{ini}}$ and $K_{\mathrm{IC}}^{\mathrm{un}}$ are decreasing gradually with the increase of relative notch depth with the relative notch depth less than 0.5 . When the relative notch depth is more than $0.3, K_{\mathrm{IC}}^{\text {ini }}$ may be not sensitive to the varying of the relative notch depth. According to the double- $K$ fracture criterion,

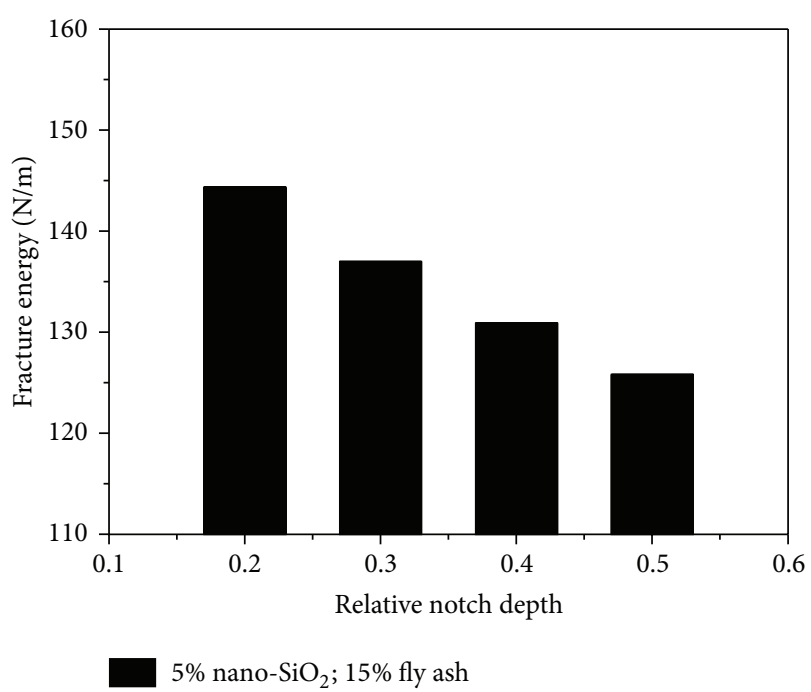

FIGURE 4: Effect of relative notch depth on fracture energy.

the concrete with larger $K_{\mathrm{IC}}^{\mathrm{ini}}$ and $K_{\mathrm{IC}}^{\mathrm{un}}$ has higher fracture properties. The variations of $K_{\mathrm{IC}}^{\mathrm{ini}}$ and $K_{\mathrm{IC}}^{\mathrm{un}}$ indicate that the fracture properties of the concrete containing nano- $\mathrm{SiO}_{2}$ and fly ash with smaller relative notch depth will be higher than the actual fracture properties of the concrete. The value of the fracture toughness of the concrete composite has great relation with the peak vertical load of the beam specimen. In general, the fracture toughness of the concrete composite is increasing with the increase of the peak vertical load. From the testing process, it can be seen that the specimen with smaller depth of the precutting crack can afford the larger peak vertical load. As a result, the $K_{\mathrm{IC}}^{\mathrm{ini}}$ and $K_{\mathrm{IC}}^{\mathrm{un}}$ decrease with the increase of relative notch depth.

3.2. Effect of Relative Notch Depth on Fracture Energy. The variations of $G_{F}$ of notched three-point bending beam specimens of the concrete containing nano- $\mathrm{SiO}_{2}$ and fly ash with $0.2,0.3,0.4$, and 0.5 relative notch depth at 28 days curing period are illustrated in Figure 4. From the figure, it can be seen that a considerable decrease for $G_{F}$ of the concrete was observed by increasing the value of relative notch depth of the notched specimen when the relative notch depth is less than 0.5. Compared with the relative notch depth of 0.2 , the decrease of $G_{F}$ was determined as $5.2 \%, 9.3 \%$, and $12.8 \%$ for the three-point bending beam specimen with $0.3,0.4$, and 0.5 relative notch depth, respectively. The value of $G_{F}$ can reflect how difficult the crack propagates, and the higher $G_{F}$ indicate that the concrete has higher fracture properties, while, on the contrary, the concrete has lower fracture properties with smaller value of $G_{F}$. Therefore, the above-mentioned variations of $G_{F}$ indicates that the fracture properties of the concrete containing nano- $\mathrm{SiO}_{2}$ and fly ash with larger relative notch depth will be lower than the actual fracture properties of the concrete. The fracture energy $G_{F}$ of concrete composite represents the energy necessary to create a unit area of fracture surface. Then the specimen with smaller relative notch depth needs more energy to create a certain 


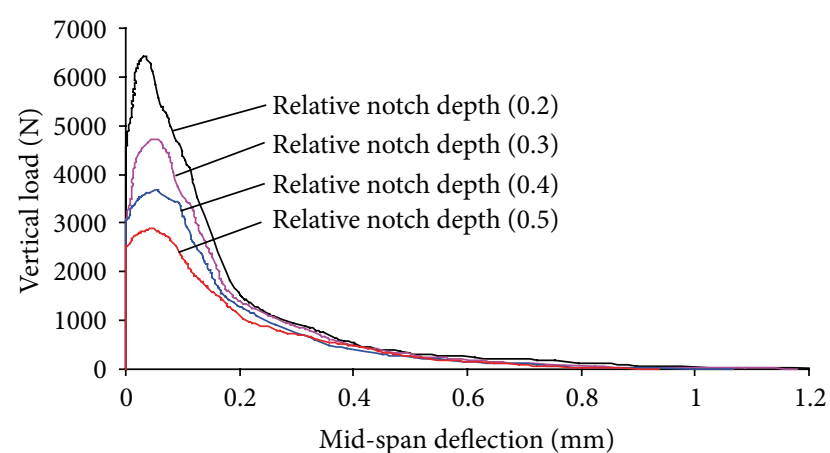

FIGURE 5: Contrast of $P_{V}-\delta$ curves of different relative notch depth.

area of fracture surface than the specimen with larger relative notch depth. The higher $G_{F}$ indicates that more energy will be consumed to make the concrete composite fracture and the concrete composite has better fracture properties. Therefore, $G_{F}$ is decreasing with the increase of the relative notch depth of the beam specimen.

Figure 5 presents the typical complete curves of $P_{V^{-}} \delta$ of the notched three-point bending beam specimens of the concrete containing nano- $\mathrm{SiO}_{2}$ and fly ash with different values of relative notch depth. From the curves, it can be seen that the nonlinear stage of the curve becomes shorter and shorter, and the descent stage of the curve becomes sharper and sharper when the relative notch depth increases from 0.2 to 0.5 . Besides, the area surrounded by the curve and the coordinate axis decreases gradually and the maximal midspan deflection also decreases gradually with the increase of the relative notch depth. Accordingly, the variation rule of the relational curves of $P_{V^{-}} \delta$ indicates that the resistance to crack propagation of the specimen is gradually decreased with the increase of relative notch depth of the specimens.

3.3. Effect of Relative Notch Depth on CMOD and CTOD. The different relational curves of $P_{V^{-}}$CMOD and $P_{V}$-CTOD of the three-point bending beam specimens of the concrete containing nano- $\mathrm{SiO}_{2}$ and fly ash at 28 days curing period with different values of relative notch depth are given in Figures 6 and 7, respectively. From the curves, it can be seen that the effect of the relative notch depth on the curves of $P_{V}$-CMOD and $P_{V}$-CTOD is significant, and the variation rules of the relational curves with the varying of relative notch depth of $P_{V}$-CMOD and $P_{V}$-CTOD are similar to those of the relational curves of $P_{V^{-}} \delta$.

Figure 8 presents the variations of the critical crack mouth opening displacement $\left(\mathrm{CMOD}_{c}\right)$ and the critical crack tip opening displacement $\left(\mathrm{CTOD}_{c}\right)$ of the three-point bending beam specimens of the concrete containing nano- $\mathrm{SiO}_{2}$ with different values of relative notch depth, respectively. The $\mathrm{CMOD}_{c}$ can be defined as the crack mouth opening displacement when the vertical load reaches the maximum value [28]. In a similar way, the $\mathrm{CTOD}_{c}$ can be defined as the crack tip opening displacement when the vertical load reaches the maximum value. It can be generally seen that the effect of the relative notch depth of the specimen on

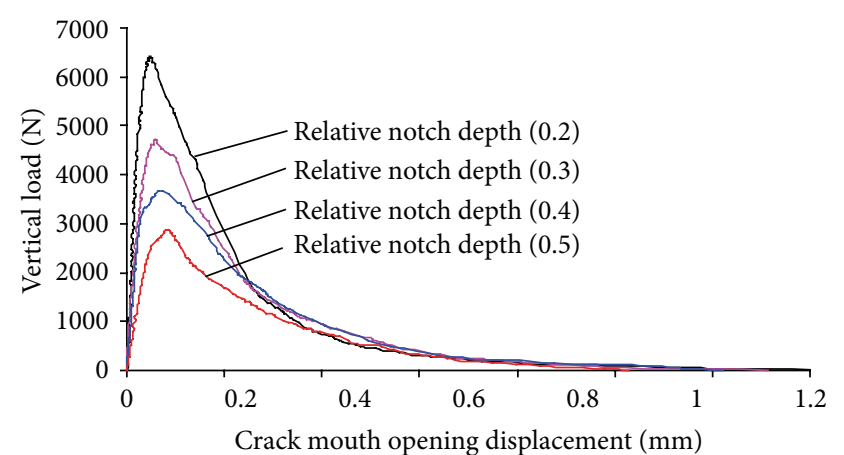

Figure 6: Contrast of $P_{V}$-CMOD curves of different relative notch depth.

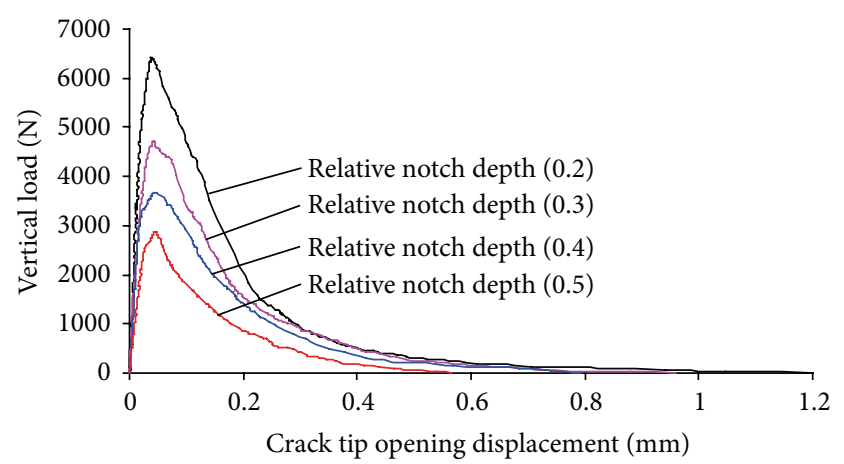

Figure 7: Contrast of $P_{V}$-CTOD curves of different relative notch depth.

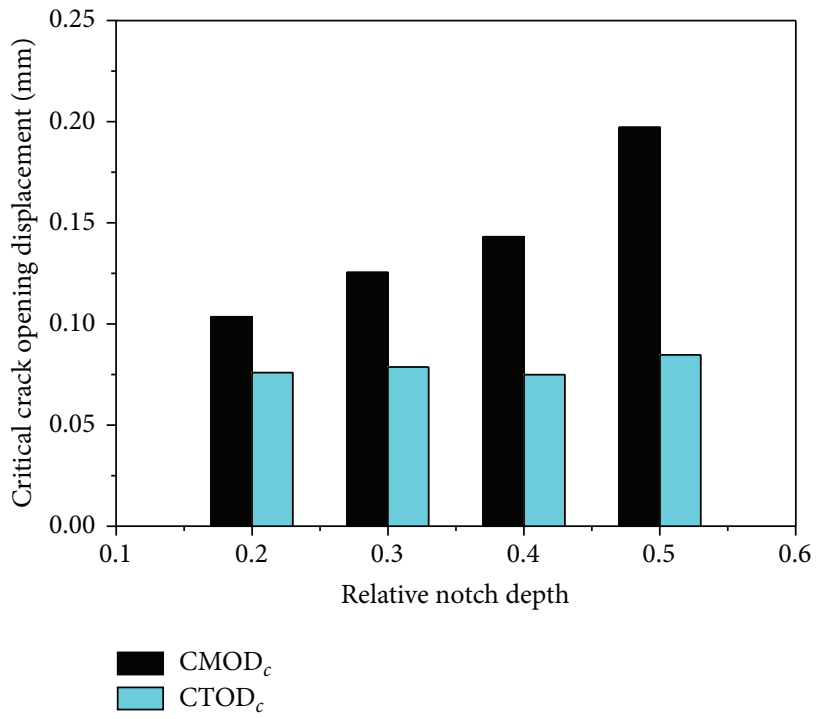

FIGURE 8: Effect of relative notch depth on $\mathrm{CMOD}_{c}$ and $\mathrm{CTOD}_{c}$.

$\mathrm{CMOD}_{c}$ is significant and $\mathrm{CMOD}_{c}$ increases gradually as the relative notch depth of the specimen increases from 0.2 to 0.5 . Compared with the three-point bending beam specimen with 0.2 relative notch depth, the increase of $\mathrm{CMOD}_{c}$ is determined as $34.6 \%$ for the three-point bending beam specimen with 0.5 relative notch depth. However, the value 
of $\mathrm{CTOD}_{c}$ changes slightly as the relative notch depth of the specimen increases from 0.2 to 0.5 . From the results of $\mathrm{CMOD}_{c}$ and $\mathrm{CTOD}_{c}$, it can be concluded that the $\mathrm{CMOD}_{c}$ is sensitive to the relative notch depth, while $\mathrm{CTOD}_{c}$ may be not sensitive to the relative notch depth of notched threepoint bending beam specimens. The variation of $\mathrm{CMOD}_{c}$ is similar to the effective crack length $a_{c}$ as the relative notch depth increases from 0.2 to 0.5 . With the relative notch depth increases, the actual crack mouth opening displacement corresponding to the peak vertical load increases gradually. However, the actual crack tip opening displacement varies a little when the vertical load reaches the peak value. For this reason, $\mathrm{CTOD}_{c}$ changes slightly as the relative notch depth of the specimen increases gradually.

\section{Conclusions}

In this study, the fracture parameters and fracture relational curves of the concrete containing nano- $\mathrm{SiO}_{2}$ and fly ash with different relative notch depth were measured by the method of notched three-point bending beam specimens. From this study, it can be concluded that the relative notch depth of notched three-point bending beam specimens has great effect on the fracture parameters of $a_{c}, K_{\mathrm{IC}}^{\mathrm{ini}}, K_{\mathrm{IC}}^{\mathrm{un}}, G_{F}$, and $\mathrm{CMOD}_{c}$ and the relational curves of $P_{V}-\delta, P_{V}$-CMOD, and $P_{V}$-CTOD of the concrete containing nano- $\mathrm{SiO}_{2}$ and fly ash. There is a tendency of increase in $a_{c}$ and $\mathrm{CMOD}_{c}$ with the increase of relative notch depth, while $K_{\mathrm{IC}}^{\mathrm{ini}}, K_{\mathrm{IC}}^{\mathrm{un}}$, and $G_{F}$ are decreasing gradually with the increase of relative notch depth of notched three-point bending beam specimens. When the relative notch depth increases from 0.2 to 0.5 , the nonlinear stage of the curve becomes shorter and shorter, and the descent stage of the curve becomes sharper and sharper. The fracture parameters of $a_{c}, K_{\mathrm{IC}}^{\mathrm{ini}}, K_{\mathrm{IC}}^{\mathrm{un}}, G_{F}$, and $\mathrm{CMOD}_{c}$ and the fracture curves are sensitive to the relative notch depth, while $\mathrm{CTOD}_{c}$ may be not sensitive to the relative notch depth of notched three-point bending beam specimens.

\section{Disclosure}

The authors declare that they have no financial or personal relationship with any person or organization that may inappropriately influence their work. There is no professional or commercial interest of any kind in all the commercial identities mentioned in their paper.

\section{Acknowledgments}

The authors would like to acknowledge the financial support received from the National Natural Science Foundation of China (Grant no. 51208472), China Postdoctoral Science Foundation (Grant no. 20110491007), the open projects funds of the dike safety and disaster prevention engineering technology research center of Chinese Ministry of Water Resources (Grant no. 201201), and the financial support received from Collaborative Innovation Center of Henan Province of Water Conservancy and Transportation Infrastructure Projects.

\section{References}

[1] A. Bilodeau and V. Mohan Malhotra, "High-volume fly ash system: concrete solution for sustainable development," ACI Structural Journal, vol. 97, no. 1, pp. 41-48, 2000.

[2] M. Arezoumandi, J. S. Volz, C. A. Ortega, and J. J. Myers, "Effect of total cementitious content on shear strength of high-volume fly ash concrete beams," Materials and Design, vol. 46, pp. 301309, 2013.

[3] M. Arezounamdi and J. S. Volz, "Effect of fly ash replacement level on the shear strength of high-volume fly ash concrete beams," Journal of Cleaner Production, vol. 59, pp. 120-130, 2013.

[4] C. H. Huang, S. K. Lin, C. S. Chang, and H. J. Chen, "Mix proportions and mechanical properties of concrete containing very high-volume of Class F fly ash," Construction and Building Materials, vol. 46, no. 10, pp. 71-78, 2013.

[5] A. Durán-Herrera, C. A. Juárez, P. Valdez, and D. P. Bentz, "Evaluation of sustainable high-volume fly ash concretes," Cement and Concrete Composites, vol. 33, no. 1, pp. 39-45, 2011.

[6] P. Zhang, Q. Li, and Z. Sun, "Influence of silica fume and polypropylene fiber on fracture properties of concrete composite containing fly ash," Journal of Reinforced Plastics and Composites, vol. 30, no. 24, pp. 1977-1988, 2011.

[7] P. Zhang, Q. Li, and H. Zhang, "Combined effect of polypropylene fiber and silica fume on mechanical properties of concrete composite containing fly ash," Journal of Reinforced Plastics and Composites, vol. 30, no. 16, pp. 1349-1358, 2011.

[8] P. Zhang, Q. Li, and Z. Sun, "Effect of polypropylene fibre on flexural properties of concrete composites containing fly ash and silica fume," Proceedings of the Institution of Mechanical Engineers L, vol. 226, no. 2, pp. 177-181.

[9] M.-H. Zhang and H. Li, "Pore structure and chloride permeability of concrete containing nano-particles for pavement," Construction and Building Materials, vol. 25, no. 2, pp. 608-616, 2011.

[10] T. Ji, "Preliminary study on the water permeability and microstructure of concrete incorporating nano- $\mathrm{SiO}_{2}$," Cement and Concrete Research, vol. 35, no. 10, pp. 1943-1947, 2005.

[11] H. Li, M.-H. Zhang, and J.-P. Ou, "Abrasion resistance of concrete containing nano-particles for pavement," Wear, vol. 260, no. 11-12, pp. 1262-1266, 2006.

[12] H. Li, M.-H. Zhang, and J.-P. Ou, "Flexural fatigue performance of concrete containing nano-particles for pavement," International Journal of Fatigue, vol. 29, no. 7, pp. 1292-1301, 2007.

[13] A. H. Shekari and M. S. Razzaghi, "Influence of nano particles on durability and mechanical properties of high performance concrete," Procedia Engineering, vol. 14, pp. 3036-3041, 2011.

[14] M.-H. Zhang and H. Li, "Pore structure and chloride permeability of concrete containing nano-particles for pavement," Construction and Building Materials, vol. 25, no. 2, pp. 608-616, 2011.

[15] H. Bahadori and P. Hosseini, "Modeling reduction of cement consumption by the aid of silica nano-particles (Investigation on concrete properties)," Journal of Civil Engineering and Management, vol. 18, no. 3, pp. 416-425, 2012.

[16] A. Naji Givi, S. Abdul Rashid, F. N. A. Aziz, and M. A. M. Salleh, "Experimental investigation of the size effects of $\mathrm{SiO}_{2}$ nano-particles on the mechanical properties of binary blended concrete," Composites B, vol. 41, no. 8, pp. 673-677, 2010.

[17] A. Naji Givi, S. Abdul Rashid, F. N. A. Aziz, and M. A. M. Salleh, "The effects of lime solution on the properties of $\mathrm{SiO}_{2}$ 
nanoparticles binary blended concrete," Composites B, vol. 42, no. 3, pp. 562-569, 2011.

[18] A. Heidari and D. Tavakoli, "A study of the mechanical properties of ground ceramic powder concrete incorporating nano$\mathrm{SiO}_{2}$ particles," Construction and Building Materials, vol. 38, pp. 255-264, 2013.

[19] G. Khalaj and A. Nazari, "Modeling split tensile strength of high strength self compacting concrete incorporating randomly oriented steel fibers and $\mathrm{SiO}_{2}$ nanoparticles," Composites $B$, vol. 43, no. 4, pp. 1887-1892, 2012.

[20] "Portland cement and ordinary portland cement," Tech. Rep. GB175-2007, National Standard of the People's Republic of China, Beijing, China, 2007.

[21] "Fly ash used for cement and concrete", Tech. Rep. GB/T, 15962005, National Standard of the People's Republic of China, Beijing, China, 2005.

[22] RILEM 50-FMC, "Determination of fracture energy of mortar and concrete by means of three-point bend tests on notched beams," Materials and Structures, vol. 18, pp. 287-290, 1985.

[23] S. Xu and H. W. Reinhardt, "A simplified method for determining double-K fracture parameters for three-point bending tests," International Journal of Fracture, vol. 104, no. 2, pp. 181-209, 2000.

[24] S.-L. Xu, Z.-M. Wu, and S.-G. Ding, "Practical analytical approach to the determination of double-K fracture parameters of concrete," Engineering Mechanics, vol. 20, no. 3, pp. 54-61, 2003.

[25] H. Rong, W. Dong, Z.-M. Wu, and X.-L. Fan, "Experimental investigation on double-k fracture parameters for large initial crack-depth ratio in concrete," Engineering Mechanics, vol. 29, no. 1, pp. 162-167, 2012.

[26] M. Elser, E. K. Tschegg, N. Finger, and S. E. Stanzl-Tschegg, "Fracture behaviour of polypropylene-fibre-reinforced concrete: modelling and computer simulation," Composites Science and Technology, vol. 56, no. 8, pp. 947-956, 1996.

[27] Y. Y. Yu, Z. Y. Zhang, G. G. Guo, R. B. Rao, and Z. J. Zhou, "Study on fracture energy GF of concrete," Shuili Xuebao, vol. 18, no. 7, pp. 300-307, 1987.

[28] P. Zhang, C. H. Liu, Q. F. Li, and P. Wang, "Effect of polypropylene fiber on fracture properties of cement treated crushed rock," Composites B, vol. 55, pp. 48-54, 2013. 

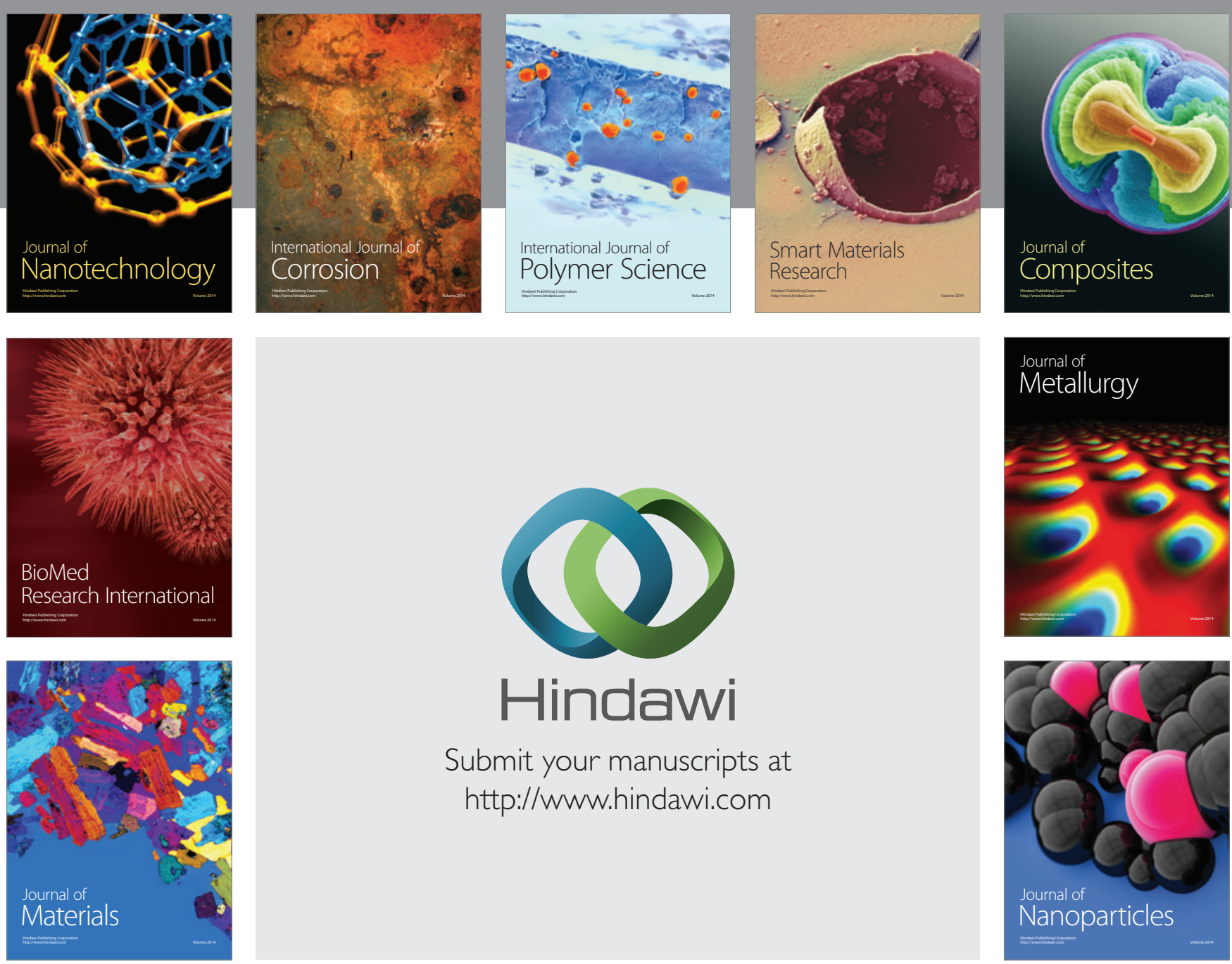

Submit your manuscripts at http://www.hindawi.com
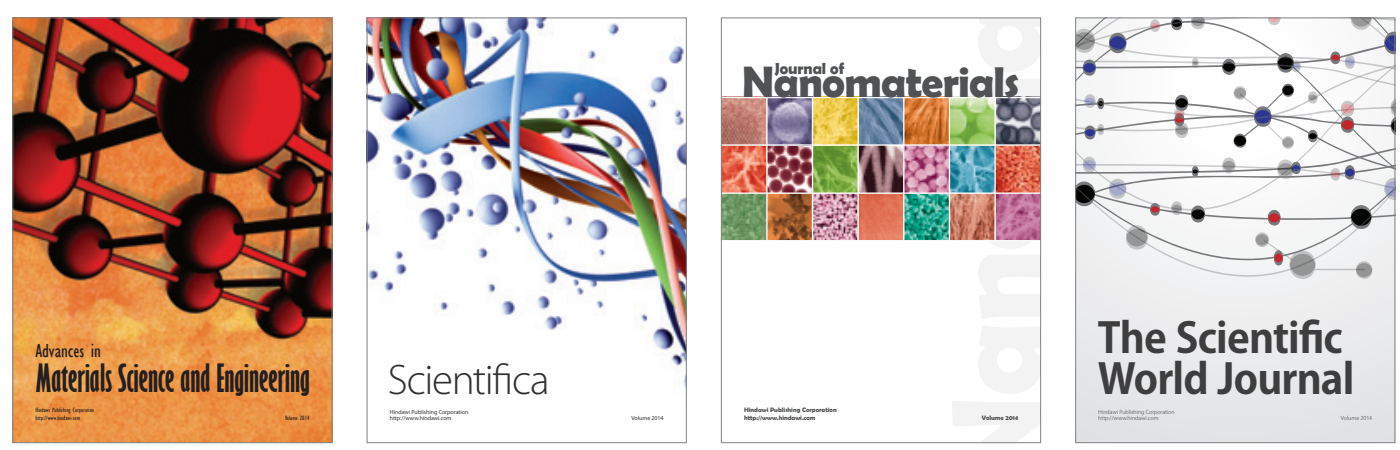

\section{The Scientific World Journal}
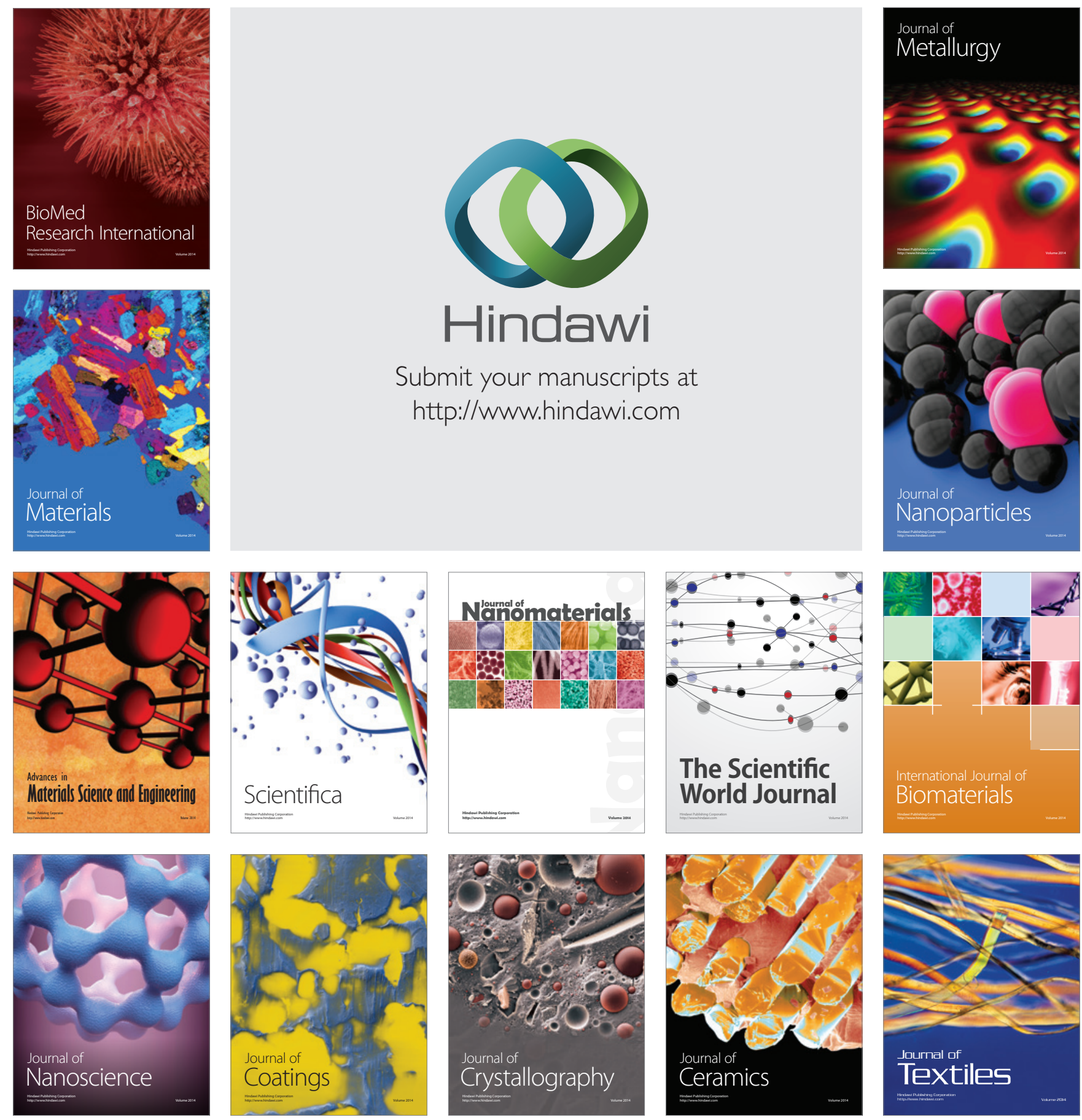